Article

\title{
Effect of Ethanol on the Textural Properties of Whey Protein and Egg White Protein Hydrogels during Water-Ethanol Solvent Exchange
}

\author{
Christian Kleemann ${ }^{1, *}$, Joël Zink ${ }^{1,2}$, Ilka Selmer ${ }^{3}{ }^{-}$, Irina Smirnova ${ }^{3}\left(\mathbb{D}\right.$ and Ulrich Kulozik ${ }^{1}(\mathbb{D}$ \\ 1 Chair of Food and Bioprocess Engineering, Technical University of Munich, Weihenstephaner Berg 1, \\ 85354 Freising, Germany; joel.zink@tum.de (J.Z.); ulrich.kulozik@tum.de (U.K.) \\ 2 Laboratory of Food Process Engineering, ETH Zürich, Schmelzbergstrasse 9, 8092 Zürich, Switzerland \\ 3 Institute of Thermal Separation Processes, Hamburg University of Technology, Eißendorfer Straße 38, \\ 21073 Hamburg, Germany; ilka.selmer@tuhh.de (I.S.); irina.smirnova@tuhh.de (I.S.) \\ * Correspondence: christian.kleemann@tum.de
}

Academic Editors: Stefano Cardea, Antonio Tabernero de Paz, Silvio A.B. Vieira de Melo and Giuseppe Cirillo

Received: 12 August 2020; Accepted: 23 September 2020; Published: 25 September 2020

\begin{abstract}
This study aims at investigating the effect of ethanol $(\mathrm{EtOH})$ on the textural properties of whey protein and egg white protein hydrogels. The hydrogels were produced by thermally induced gel formation of aqueous protein solutions. The water contained in the gel network was subsequently exchanged by EtOH to assess structural changes upon exposure of hydrogels to ethanolic aqueous phases. The textural properties of the hydrogel and alcogel samples were analyzed by uniaxial compression tests. For both protein sources, the hardness increased exponentially when $\mathrm{pH}$ and $\mathrm{EtOH}$ concentration were increased. This increase correlated with a shrinkage of the gel samples. The gel texture was found to be elastic at low $\mathrm{EtOH}$ concentrations and became stiff and hard at higher $\mathrm{EtOH}$ concentrations. It was found that the solvent exchange influences the ion concentration within the gels and, therefore, the interactions between molecules in the gel structure. Non-covalent bonds were identified as substantially responsible for the gel structure.
\end{abstract}

Keywords: ethanol-protein interaction; gel stability; gel shrinkage; alcogel; aerogel

\section{Introduction}

The effect of ethanol (EtOH) on proteins in solution as well as on resulting protein or polysaccharide gels has been studied by various works for several reasons. Applications, where an understanding of changes induced by $\mathrm{EtOH}$ on proteins is of relevance, are the disinfecting properties of $\mathrm{EtOH}$, where it is highly effective against enveloped viruses [1]. The use of alginate gels as super-absorbent for EtOH containing aqueous solutions has been studied by Moe et al. [2]. In food products, protein gels may be used itself as semi-solid food containing alcohol or as a carrier system for microorganisms in fermentation processes producing $\mathrm{EtOH}$, where a change of the gel structure induced by variable $\mathrm{EtOH}$ weight fractions may have negative effects on the fermentation process [3].

A protein hydrogel can be described as a porous matrix and networked structure completely soaked with water as a gel solvent. Hydrogels also function as precursors of aerogels, following solvent exchange by ethanol (EtOH) and supercritical $\mathrm{CO}_{2}$ extraction [4-7]. The dry protein network structure has an extremely high inner porosity and high specific inner surface area [4]. As a carrier system, this surface area may be impregnated with large amounts of a valuable component requiring protection against adverse conditions in the environment [8]. Before hydrogels can be converted into an aerogel, exchanging the contained water entirely by $\mathrm{CO}_{2}$-soluble EtOH is necessary [6]. However, the gel is postulated to undergo structural changes during the solvent exchange step of the water with a 
$\mathrm{CO}_{2}$-soluble solvent like EtOH and the $\mathrm{scCO}_{2}$-drying step [9], but it is unclear whether the structural changes occur on the way from the hydrogel to the alcogel or from the alcogel to the aerogel. The effect of $\mathrm{EtOH}$ on stabilizing binding forces in the hydro- and alco-gel respectively, is not well understood $[10,11]$.

Heat-denatured protein gels often obtain their structural stability through covalent bonds in the form of disulfide bridges or non-covalent molecular interactions (electrostatic and hydrophobic interactions, hydrogen bonds), depending on the nature of the protein [12]. Non-covalent molecular interactions are particularly influenced by the solvent exchange. EtOH has a much lower relative permittivity than water, which influences electrostatic interactions [13]. In addition, water interacts much stronger with the nonpolar solvent than with the proteins [14]. A denaturing effect, which puts the protein molecules in the molten globule intermediate state has also been reported for organic solvents [15]. Therefore, protein molecules dissolved in aqueous solution aggregate and subsequently, precipitate, when $\mathrm{EtOH}$ is added to the solution, because hydrophobic interactions increase.

Reports related to the effect of EtOH on proteins in solution or also on polysaccharides already in gel state at various environmental conditions $[1,2,16,17]$ do not allow for a prediction of the behavior of milk protein and hens' egg white protein gels produced by thermally induced gel formation. The purpose of this study therefore was to assess the effect of $\mathrm{EtOH}$ on such gels after the aqueous protein solution has been gelled by heat treatment. Other studies have focused on the effect of EtOH on proteins in solution, prior to gel formation. The methods used to assess potential structural or molecular changes, like circular dichroism $[1,15]$, cannot be applied to ready set gels, because the protein molecules are bound to the protein network structure. The hypothesis was that certain EtOH concentrations and $\mathrm{pH}$ levels can be expected to lead to different properties of the alcogels due to the impact of $\mathrm{EtOH}$ on existing and developing non-covalent bonds. It was expected that egg white protein (EWP) and whey protein isolate (WPI) yield different gel properties, because the individual proteins contained in the complex EWP and WPI systems have different properties and, therefore, should react differently when the already structured proteins in gel state, thermally produced in environments of different $\mathrm{pH}$, are immersed in $\mathrm{EtOH}$. The aim and the point of difference of this study was to extend the existing knowledge on the presence of $\mathrm{EtOH}$ prior to and during gel formation. Furthermore, the fate of ions contained within the protein networks upon solvent exchange was assessed. Knowledge about potential shifts in the ion concentration was expected to yield novel insights regarding ionic retention or washing out effects during the solvent exchange. Protein-protein interactions are known to depend on the polarity of the solvent and their ionic environment. With the results obtained, a gap in knowledge is intended to be closed since changes observed in the final aerogel were attributed to the overall process, not differentiating between changes from the protein hydro- to the alco-gel.

The approach was as follows: Heat-denatured WPI and EWP hydrogels of different $\mathrm{pH}$ were immersed in ethanolic aqueous solutions containing EtOH concentrations of 60-100\%. Textural changes were analyzed with uniaxial compression tests to measure the sample height, the hardness and elasticity of the gels. To determine the amounts of ions dissolved from the gel matrix during solvent exchange, a method was developed to measure the cation content in the surrounding exchange solution using high-pressure liquid chromatography (HPLC).

\section{Results}

\subsection{Shrinkage of Protein Hydrogel Spheres as A Function of Ethanol Concentration and $p H$ during Thermal Gel Formation}

The solvent exchange was conducted by immersing the gel in an aqueous EtOH solution with a concentration of $60 \%$ to $100 \% \mathrm{EtOH}$. The exchange solution was renewed four times after at least $4 \mathrm{~h}$, i.e., when equilibrium was reached. A constant $\mathrm{EtOH}$ weight fraction in the surrounding solution was taken as an indicator for a completed solvent exchange. In all experiments, the final EtOH concentration was at least $99 \%$ of the target concentration.

The volumetric changes were determined by measuring the diameter of the spherical gel samples in order to investigate swelling or shrinkage of the gels. The volume of the alcogels after the solvent 
exchange was related to the volume of the respective hydrogel samples. In Figure 1, the relative sample volume is depicted as a function of $\mathrm{EtOH}$ weight fraction in the aqueous solution.

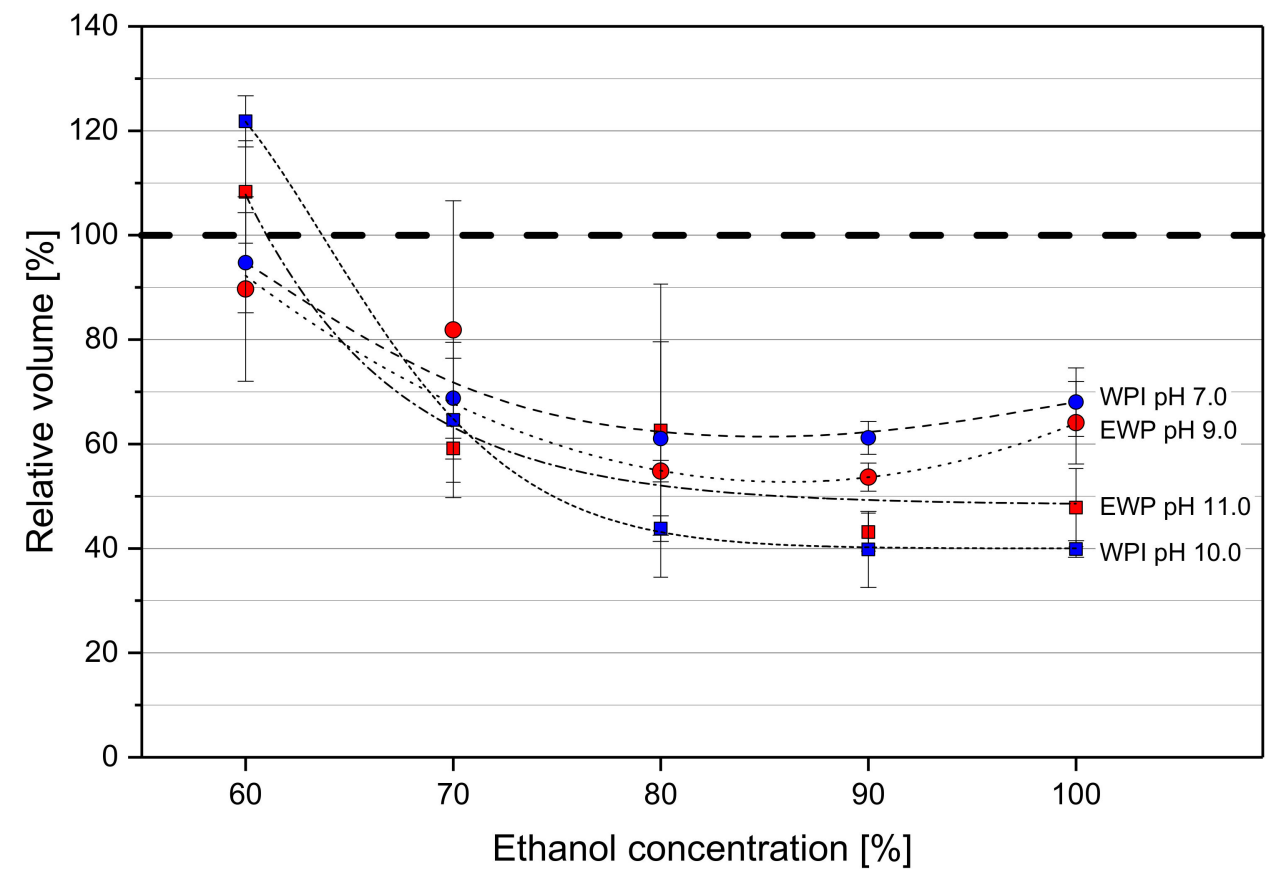

Figure 1. Relative volume of gel sphere samples after immersion in the respective aqueous ethanol $(\mathrm{EtOH})$ solution. WPI gel samples are marked in blue, and EWP samples are red. Circles represent the native $\mathrm{pH}$, squares represent alkaline conditions. Dashed lines are a guide to the eye.

EtOH weight fractions around 60\% were determined as being near the threshold between swelling and shrinkage of the gel spheres, independent of the type of protein and $\mathrm{pH}$ prior to gel formation. At $60 \% \mathrm{EtOH}$, gels revealed slight shrinkage at their native $\mathrm{pH}$, whereas gels with an alkaline $\mathrm{pH}$ even gained some volume. Immersing the same gels in deionized water led to extensive swelling with a volume increase of $236 \% \pm 41 \%$ (EWP) and $376 \% \pm 15 \%$ (WPI) at native $\mathrm{pH}$. The swelling of gels formed at alkaline $\mathrm{pH}$ was even more pronounced, with $873 \% \pm 39 \%$ (EWP) and $644 \% \pm 99 \%$ (WPI).

EtOH concentrations above $60 \%$ reduced the volume of the gel spheres. The shrinkage was more pronounced for gel spheres formed in alkaline environment. The final relative volume of gels at the protein solution's native $\mathrm{pH}$ was around $65 \%$. The most extensive shrinkage was observed for WPI gels with $\mathrm{pH} 10.0$. At $100 \% \mathrm{EtOH}$, their size was only $40 \%$ of their initial volume. The data points indicate that extensive shrinkage happens up to an $\mathrm{EtOH}$ weight fraction of $80 \%$. Higher EtOH concentrations did not lead to further shrinkage. The higher standard deviations up to $80 \% \mathrm{EtOH}$ can be explained by the very soft gel structure, which causes more variability in measuring the diameter. The harder gel structures at higher EtOH concentrations reduce the variability. The volume changes observed were in the first place determined by the $\mathrm{pH}$ of the protein solution prior to gel formation. An effect of the type of protein on the volume change was not observed.

\subsection{Hardening of Gel Spheres Induced by EtOH}

The solvent exchange from water to $\mathrm{EtOH}$ had an evident impact on the hardness of the gel spheres. No fracture peaks were detected by the texture analyzer for all tested protein gels when the samples were compressed by $60 \%$ of their original height. This was true for all tested $\mathrm{pH}$ values and was independent of EtOH concentration. The necessary force for compression as a function of EtOH weight fraction in the surrounding solution at the end of the solvent exchange is depicted in Figure 2 for varying types of protein and $\mathrm{pH}$ values. 


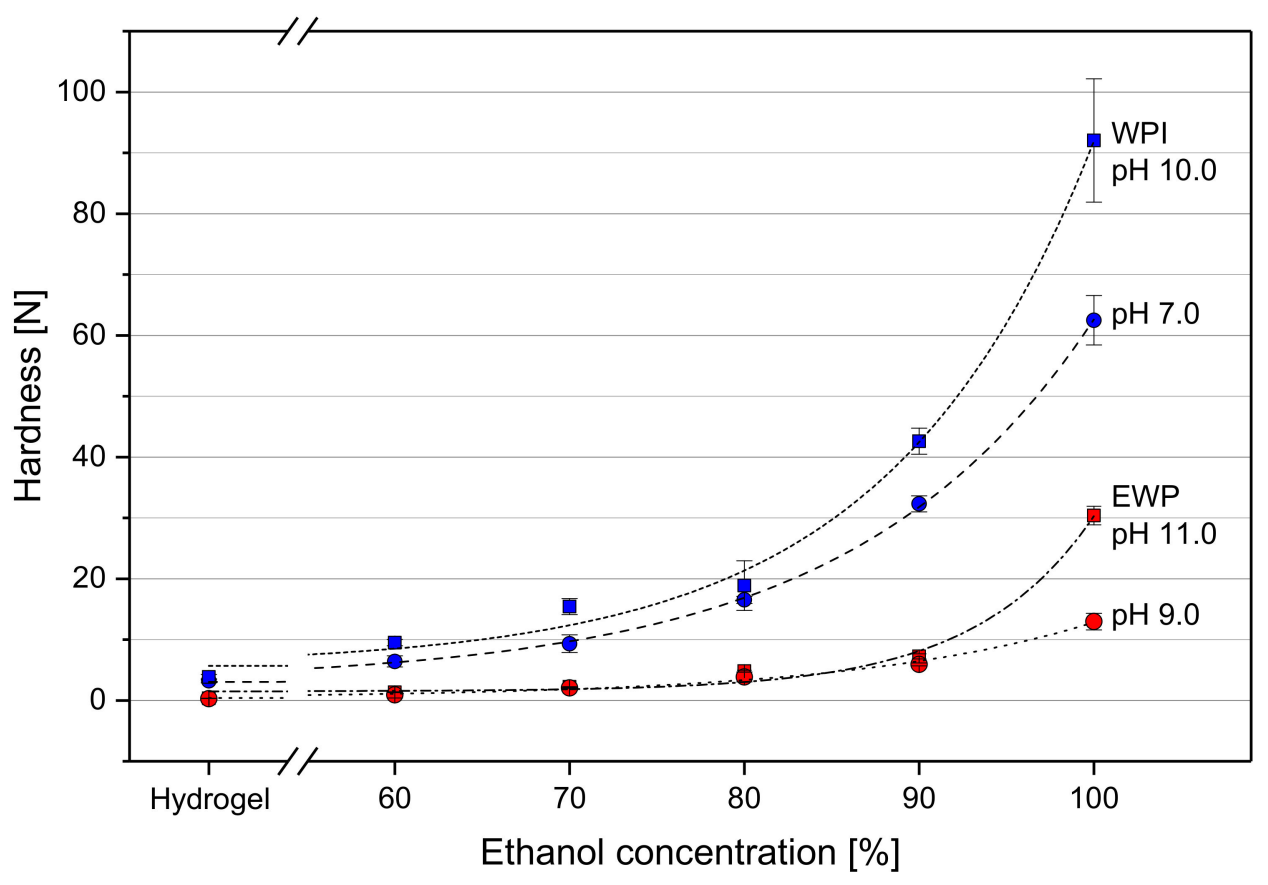

Figure 2. Hardness as the necessary force for compression of the gel spheres to $60 \%$ of their original height as a function of EtOH weight fraction in the gel after solvent exchange. WPI gel samples are marked in blue, EWP samples are in red. Circles represent the native $\mathrm{pH}$, squares represent alkaline conditions. Dashed lines were added as guide to the eye.

The untreated hydrogels were soft and could be deformed with a relatively low uniaxial compression force. The absolute forces needed to compress WPI hydrogels were $3.22 \pm 0.34 \mathrm{~N}$ and $3.84 \pm 0.44 \mathrm{~N}$ for $\mathrm{pH} 7.0$ and $\mathrm{pH} 10.0$, respectively. These values are about ten times higher in comparison to EWP gels, where $0.29 \pm 0.02 \mathrm{~N}$ were required for $\mathrm{pH} 9.0$ and $0.35 \pm 0.01 \mathrm{~N}$ for $\mathrm{pH} 11.0$.

Independently of protein type and $\mathrm{pH}$, an exponential increase in compression force was detected in all cases with increasing EtOH concentration. This effect was more pronounced for gels formed in alkaline environment. After the solvent exchange with an aqueous solution with $60 \% \mathrm{EtOH}(w / w)$, the gels required only slightly more force for the same deformation compared to the hydrogels. A moderate increase of the necessary compression force was needed up to $80 \% \mathrm{EtOH}$. At $100 \% \mathrm{EtOH}$, the necessary compression force was at least ten times higher compared to an EtOH concentration of $60 \%$. WPI gels reacted stronger to the presence of EtOH than EWP gels. The necessary compression force was about 3 to 4 times higher for WPI gels.

\subsection{Effect of EtOH on Elasticity of Gel Spheres}

The elasticity of the gels as a function of $\mathrm{EtOH}$ weight fraction, protein type and $\mathrm{pH}$ at gel formation was determined by a texture profile analysis (TPA). The values of elasticity are shown in Figure 3 as the ratio of the height of the sample at the beginning of the second to the first compression cycle of the TPA. An elasticity value of 1.00 describes a sample that completely regains its original height between the two compression cycles. This would indicate that the cross-links between the molecules within the gel network are not affected during compression and are able to force the gel back to the state prior to deformation before the second compression cycle begins. 


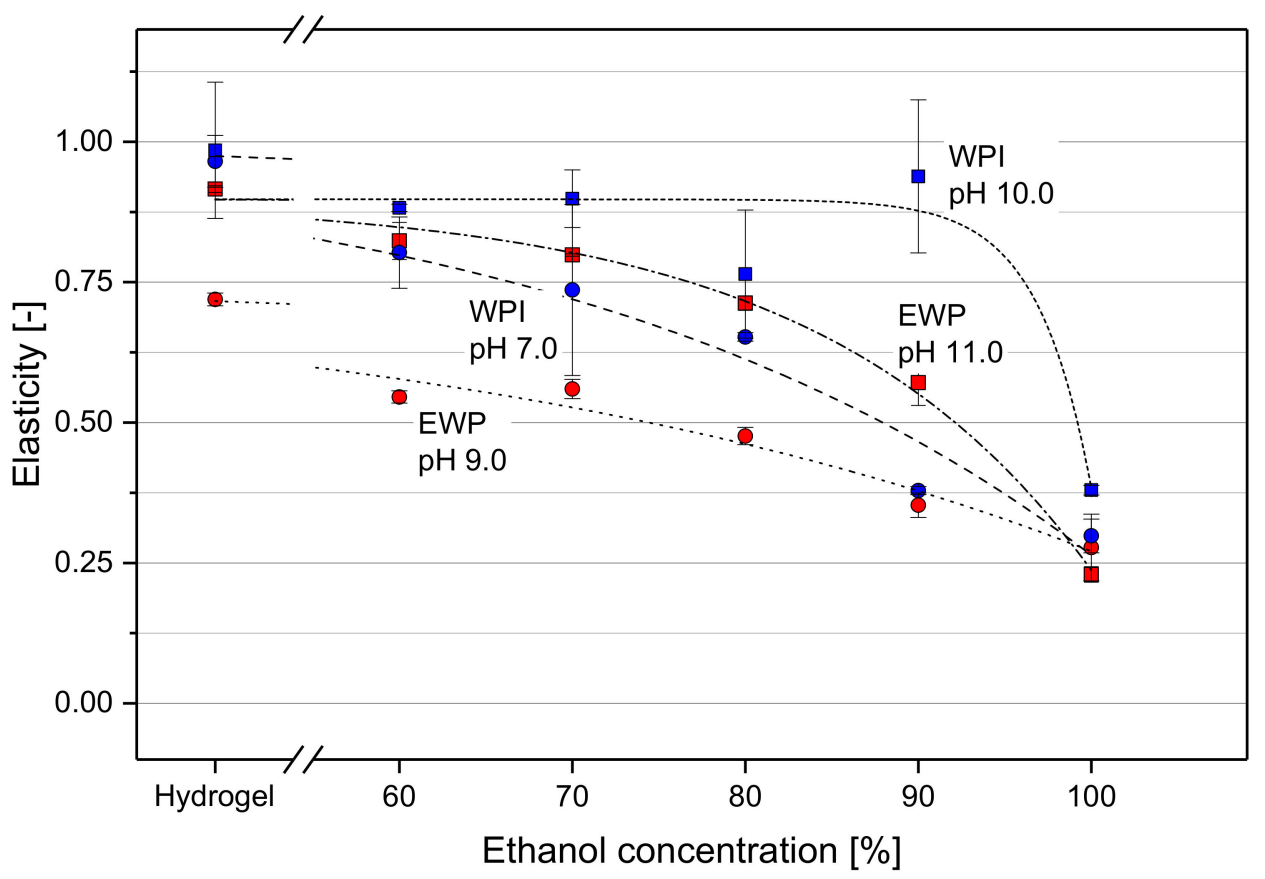

Figure 3. Elasticity of gel spheres as a function of EtOH weight fraction in the gel after solvent exchange. Blue symbols represent WPI gels, red symbols EWP gels. Circles are for native $\mathrm{pH}$, squares for alkaline $\mathrm{pH}$ values. Dashed lines are a guide to the eye, only.

Nearly full elastic recovery was observed for WPI hydrogels at pH 7.0 and 10.0, and EWP hydrogels at $\mathrm{pH}$ 11.0. Their textural elasticity values were between 0.91 and 0.99 , which shows that a strain of $60 \%$ was within the range of elastic deformation for those gels. Only the $\mathrm{pH} 9.0 \mathrm{EWP}$ hydrogel showed a substantially lower elasticity, with only 0.72 . The measured elasticity was lower for all tested types of gel when the solvent exchange to $\mathrm{EtOH}$ was conducted and deformation became plastic. This was especially the case for the $\mathrm{pH}$ 9.0 EWP samples. With increasing EtOH concentration, the elasticity dropped down to about 0.25. This was also the case for the pH 11.0 EWP gel and the pH 7.0 WPI gel, but the drop to lower elasticity values occurred at higher EtOH concentrations. The high elastic property was best maintained for WPI gels with $\mathrm{pH}$ 10.0. An EtOH concentration above $90 \%$ was necessary to decrease the elasticity of those gels. At $100 \% \mathrm{EtOH}$, a sudden decrease of elasticity was observed with a final elasticity of 0.37 , which is in the range of the other three tested gels.

\subsection{Interaction of Ions Contained in the Protein Gel with the Exchange Solution}

The ion concentration within a protein gel influences the interactions between the proteins and has an effect on the gel hardness and elasticity. It was analyzed whether ions dissolve in the exchange solution or remain in the protein gel, which is an indirect measure of the ion concentration within the gel. The amounts of ions in the exchange solutions relative to the ones in the protein gel prior to the solvent exchange are listed in Table 1. The intention was to understand how the solvent exchange influences the ion concentration within the gel and to identify differences between WPI and EWP gels. Both gels were analyzed at their native $\mathrm{pH}$ of 7.0 (WPI) and 9.0 (EWP).

Table 1. Ions contained in exchange solution after $24 \mathrm{~h}$ of solvent exchange.

\begin{tabular}{cccccc}
\hline Exchange Solvent & $\begin{array}{c}\text { WPI pH 7.0 } \\
\mathbf{N a}^{+} \mathbf{( \% )}\end{array}$ & $\begin{array}{c}\text { WPI pH 7.0 } \\
\mathbf{C a}^{2+} \mathbf{( \% )}\end{array}$ & $\begin{array}{c}\text { EWP pH 9.0 } \\
\mathbf{N a}^{+} \mathbf{( \% )}\end{array}$ & $\begin{array}{c}\text { EWP pH 9.0 } \\
\mathbf{K}^{+} \mathbf{( \% )}\end{array}$ & $\begin{array}{c}\text { EWP pH 9.0 } \\
\mathbf{C a}^{2+} \mathbf{( \% )}\end{array}$ \\
\hline $\mathrm{H}_{2} \mathrm{O}$ & $81.9 \pm 4.6$ & $32.5 \pm 2.1$ & $98.3 \pm 2.8$ & $83.5 \pm 2.0$ & $91.0 \pm 21.7$ \\
$\mathrm{EtOH} \mathrm{60 \%}$ & $35.1 \pm 2.1$ & $9.6 \pm 1.0$ & $88.3 \pm 1.1$ & $77.0 \pm 1.0$ & $14.2 \pm 0.2$ \\
$\mathrm{EtOH} 100 \%$ & $4.4 \pm 1.1$ & $1.2 \pm 0.8$ & $65.0 \pm 1.0$ & $57.3 \pm 1.3$ & $31.4 \pm 2.8$ \\
\hline
\end{tabular}


All exchange solutions were ion-free at the beginning of the solvent exchange. Therefore, all ions detected in the exchange solution after the solvent exchange diffused from the gel into the surrounding liquid. When the gel spheres were immersed in deionized water, over $80 \%$ of the ions initially added with the gel spheres were found in the exchange solution. The ions interacted stronger with deionized water as a solvent than with the proteins in the gel. A stronger interaction was observed between WPI gel proteins and $\mathrm{Ca}^{2+}$ ions. Only a little above $30 \%$ of the $\mathrm{Ca}^{2+}$ ions diffused from the gel into the exchange solution. With an increasing EtOH-concentration, the concentration of cations found in the solvent after the exchange decreased. In the case of WPI gels, nearly all ions remained within the gel when the solvent was $100 \% \mathrm{EtOH}$. The interactions between the ions and the proteins are stronger than with the solvent. The same trend was observed for EWP gels. Only the results of $\mathrm{Ca}^{2+}$ ions (Table 1, last column) do not strictly follow this trend. The generally very low concentration of $\mathrm{Ca}^{2+}$ ions in EWP (less than $1 \%$ of $\mathrm{Na}^{+}$-concentration) brought along an uncertainty in the analytical values. However, the amounts of ions solubilized from the EWP gels in the ethanolic solvent was higher compared to WPI gels. The results indicate that the ionic environment within EWP gels is more strongly influenced by a solvent exchange compared to WPI gels, because more ions were detected in the exchange solution.

\section{Discussion}

Shrinkage on one hand and harder gels on the other hand upon solvent exchange were observed for all tested gel samples, starting with an $\mathrm{EtOH}$ weight fraction of $60 \%$. Extensive swelling was observed in deionized water. Therefore, it can be assumed that around an $\mathrm{EtOH}$ concentration of $60 \%$, the attracting forces, namely hydrophobic interactions and hydrogen bonds, start to compensate the repulsive forces, mainly electrostatic repulsion, between molecules in the protein gel structure. Those non-covalent interactions are predominantly responsible for the hardness of heat-induced protein gels [12]. This effect of EtOH on protein gels from whey or egg white, which were gelled prior to contact with $\mathrm{EtOH}$, has not been investigated so far. A comparable distinct threshold between swelling and shrinkage has been reported for polysaccharide gels from gelatin, Na-alginate and $k$-carrageenan in the literature $[2,3,17]$. Yoshizawa et al. [1] reported a precipitation of bovine serum albumin molecules in solution at or above an $\mathrm{EtOH}$ weight fraction of $60 \%$. An $\mathrm{EtOH}$ fraction of $50 \%(v / v)$ can also be used to induce gelation of whey protein solutions without heat treatment [18]. An increasing hardness of WPI gels for increased EtOH weight fractions was also measured by Zirbel and Kinsella [19]. In their study, the researchers added EtOH to WPI solutions before heat-induced gelation. In comparison to the results presented here, the intermolecular interactions were influenced by $\mathrm{EtOH}$ prior to forming covalent and non-covalent bonds. Uversky et al. [15] reported that EtOH induces a similar molten globule state as thermal heat treatment, which leads to exposed hydrophobic regions of the protein, usually buried within the globular structure. Hydrophobic interactions then lead to aggregation. The structural changes on secondary protein structure or the electrostatic interactions, which have been observed for whey and egg white proteins in ethanolic solution [15,20-22], seem to apply in a similar way to the heat set whey and egg white gels in this study.

$\mathrm{EtOH}$ with its low relative permittivity leads to stronger electrostatic interactions between the proteins, which have a negative net charge, due to a $\mathrm{pH}$ above the isoelectric point (pI) during gel formation, and the ions within the solvent [23]. The pI of proteins contained in EWP ranges between 4.1 and 10.7, whereas the proteins accounting for over $75 \%$ of the total dry mass have a pI of 4.1 to 6.1. [24]. The $\mathrm{pI}$ of proteins contained in WPI systems ranges between 4.2 and 8.8 , and $\alpha$-lactalbumin and $\beta$-lactoglobulin, which account for over $70 \%$ of the total dry mass, have a pI of 4.2 to 5.1 [25]. Due to the reduced relative permittivity, the counter-ions to the protein charges lose their mobility and accumulate at charged amino acid side chains, and dipole-dipole interactions occur, as proposed by Khokhlov et al. [26], while repulsive electrostatic forces are diminished. This leads to a denser packing of the molecules and the formation of new and stronger hydrophobic interactions and hydrogen bonds, resulting in shrinkage and hardening of the gel structure. The results in Table 1 showed that without 
$\mathrm{EtOH}$, most cations diffused from the gel matrix into the surrounding water. This reduced the ion concentration within the gel. This diminished the shielding effect on repulsive forces between equally charged protein molecules. The increasing repulsive forces in the gel network contribute to the extensive swelling behavior of protein gels in aqueous solutions in addition to the mechanisms described by Betz et al. [27] and Gunasekaran et al. [28]. With increasing EtOH concentration, the concentration of cations found in the exchange solution was reduced. The results indicate that the ions interact more strongly with the proteins at higher EtOH concentrations than with the solvent. A major contribution to this effect was also seen in the very low solubility of ions in EtOH-containing solvents [29]. The ions remain within the gel and, in addition, their effect on protein-protein interactions is enhanced by the low relative permittivity of $\mathrm{EtOH}$. It is known that a high ion concentration supports the aggregation of proteins [30,31]. The fate of ions within the gel structure during solvent exchange with EtOH, therefore, supports the shrinkage and hardening of the protein gels.

A special role can be attributed to $\mathrm{Ca}^{2+}$ in WPI gels, where the ions interact very strongly with the proteins, thus, substantially less $\mathrm{Ca}^{2+}$ was found in the surrounding water. This can be explained by the divalent nature of $\mathrm{Ca}^{2+}$. This enables this cation to form strong Ca-bridges between the negatively charged amino acid residues [32].

More cations have been found in the exchange solution of EWP gels (see Table 1). This would generally lead to a reduction of the shielding effect and the repulsive electrostatic forces of the negatively charged molecules have a larger effect, which, in turn, leads to swelling and softening of the gels. However, shrinkage and hardening were still observed for EWP gels (Figures 1 and 2). The denaturing effect of $\mathrm{EtOH}$ and its lower relative permittivity, which strengthens the interactions between molecules and remaining ions, seem to outweigh the reduced ion concentration within the gel.

Shrinkage and hardening of the gel spheres were more pronounced when the hydrogels were formed in strong alkaline environment (Figures 1 and 2). This was attributed to the more ordered filamentous gel structure in strong alkaline conditions. Due to the high negative net charge of protein molecules in an environment far more alkaline than the $\mathrm{pI}$, an aggregation of the protein molecules takes place in long chain-like structures. The number of covalent disulfide bonds increases due to a higher reactivity of thiol groups at alkaline $\mathrm{pH}$. The number of non-covalent bonds, like hydrophobic interactions or hydrogen bonds, decreases due to the strong repulsive electrostatic interactions. The final gel has a structure composed of stranded aggregates [33]. A random aggregation of the molecules is reduced, as it occurs with a $\mathrm{pH}$ closer to the $\mathrm{pI}$ during gel formation due to the more neutral net charge. This aggregation takes place when the non-covalent bonds are enhanced by the addition of EtOH. In addition, the particles of a particulate gel, generated at a gel forming pH closer to the pI [34], prevent a packing as dense as in the alkaline gel structure. The particles function as spacers in the gel network structure and larger cavities remain in the structure. This yields less shrinkage of the gels and a softer gel structure at a high EtOH concentration for gels with a lower pH. It is known that EtOH may raise the $\mathrm{pI}$ of proteins, because it slightly raises the $\mathrm{pK}_{\mathrm{a}}$ values of amino acid side chains $[35,36]$. The $\mathrm{pH}$ of the gels, however, was in an alkaline region with an explicit gap to the pI. Due to the complex protein systems of WPI and EWP, containing a large number of proteins, a discussion of single $\mathrm{pK}_{\mathrm{a}}$ values is not conducive. The results indicate that the $\mathrm{pH}$ during gel formation, which influences the net charge of the proteins and, therefore, a different gel structure, has a clear effect on the changes in gels induced by EtOH. This can be of high relevance in applications where protein gels are used as a carrier system for active microorganisms in continuous fermentation processes of EtOH. The dense structure of gels formed in very alkaline conditions would diminish the diffusion of substrate and product. To tailor gel properties to certain requirements, an adequate EtOH concentration and $\mathrm{pH}$ could be chosen based on the results presented here.

Furthermore, it was observed that the increase of hardness, determined for an increasing EtOH concentration, was not linear but rose exponentially (Figure 2). This was not expected from the volumetric change data shown in Figure 1. There was no considerable change of volume observed at $\mathrm{EtOH}$ weight fractions above $80 \%$. This would have suggested that there would also be no more 
change in hardness at higher EtOH concentrations. In contrast, the hardness at $100 \% \mathrm{EtOH}$ was threeto six-fold higher than at $80 \%$. This is a clear indication that the gain in hardness is not a direct result of the loss of volume, attended by a higher density of the gel structure. It is rather a result of enhanced non-covalent cross-linking and, thus, of a restructuring of the protein network.

A characteristic of gels is that they enclose a large amount of solvent. This permits a high structural flexibility of the molecules despite being less mobile in the protein network. With the results presented, it can therefore be stated that the effects of EtOH on gel hardness observed by Zirbel and Kinsella [19], who added EtOH prior to heat set gelation, or Dufour et al. [18] and Yao et al. [20], who induced protein gelation by the addition of $\mathrm{EtOH}$, also apply to hydrogels after heat set gelation. The high elasticity of hydrogels (Figure 3) gives an impression of this structural flexibility. The hydrogels regained their original height after deformation, which is expressed in an elasticity value close to 1.0. This applies to gels formed in a strong alkaline environment in particular. This is attributed to an easy displacement of the filamentous strands against each other, which, in addition, are negatively charged. The repulsive forces between these equally charged molecules allow deformation without irreversible destruction of the gel network. Furthermore, the alkaline $\mathrm{pH}$ promotes thiol-disulfide exchange reactions [37], which contribute to the gel structure and stability. Those covalent bonds do not break up during deformation. Therefore, an important role was attributed to those covalent bonds in helping the gel body to regain its original size after compression of hydrogels. The lowest elasticity values were measured for EWP hydrogels at $\mathrm{pH}$ 9.0. This was attributed to the more particulate structure of these gels, which becomes evident by their opaque appearance, as discussed above. The dominating intermolecular forces are of hydrophobic character, hydrogen bonds and dipole-dipole and electrostatic interactions. The less alkaline environment led to a lower reactivity of thiol groups and less covalent bonds developed. The non-covalent cross-links in the more particulate network structure broke during deformation, and this destruction is not reversible.

With an increasing EtOH concentration, the deformation of all tested gels becomes more permanent. The non-covalent bonds stabilizing the gel become stronger, due to the influence of $\mathrm{EtOH}$ on protein-protein interactions. They rearrange between displaced protein strands after application of mechanical stress on the hydrogel. The newly created non-covalent cross-links hold the gel in the deformed position, which results in low elasticity values.

The WPI pH 10.0 gels only lost their elasticity at very high EtOH concentrations. The strong electrostatic repulsion due to the high negative net charge in alkaline environment prevented extensive formation of new non-covalent molecular cross-links up to $90 \% \mathrm{EtOH}$. Even at this high EtOH concentration, the protein strands evidently permitted a displacement parallel to each other during compression without irreversible destruction of the gel network. The network components were forced back to their original position after the deformation cycle. Only at an EtOH concentration of $100 \%$ the interactions did become strong enough to eliminate the elastic properties almost completely. This sudden loss of elasticity coincided with an exponential increase of hardness at high EtOH weight fractions (see Figure 2).

The results presented here show that a transition from a very soft to a very hard gel occurs during a solvent exchange from a hydrogel to an alcogel. This change from a soft and elastic gel structure to a hard and robust structure was also observed in the process of creating protein aerogels [4,6], but it was unclear whether the hardening effect occurs already during solvent exchange or afterwards during $\mathrm{scCO}_{2}$ drying. An effect of the $\mathrm{pH}$ during gel formation was also observed, where the hydrogels became softer with increasing $\mathrm{pH}$. The opposite was true for the corresponding aerogels, which become much harder with increasing $\mathrm{pH}$ [38]. Table 2 shows the stiffness (calculated as required force per distance of deformation) of the hydrogels and alcogels compared to published values for aerogels. 
Table 2. Stiffness of gels in hydrogel, alcogel and aerogel state, calculated as required force per distance of deformation.

\begin{tabular}{ccccc}
\hline & \multicolumn{3}{c}{ EWP } & \multicolumn{2}{c}{ WPI } \\
Gel State & $\begin{array}{c}\mathbf{p H ~ 9 . 0} \\
\mathbf{( N / m m )}\end{array}$ & $\begin{array}{c}\mathbf{p H ~ 1 1 . 0} \\
\mathbf{( N / m m )}\end{array}$ & $\begin{array}{c}\mathbf{p H ~ 7 . 0} \\
\mathbf{( N / m m )}\end{array}$ & $\begin{array}{c}\mathbf{p H ~ 1 0 . 0} \\
\mathbf{( N / m m )}\end{array}$ \\
\hline Hydrogel & $0.12 \pm 0.01$ & $0.15 \pm 0.00$ & $1.11 \pm 0.12$ & $1.33 \pm 0.13$ \\
Alcogel & $5.6 \pm 0.8$ & $15.0 \pm 0.9$ & $25.2 \pm 2.3$ & $41.0 \pm 5.7$ \\
Aerogel & $12.5 \pm 2.9^{1}$ & $21.6 \pm 1.6^{1}$ & $148.9 \pm 16.9^{2}$ & $180.5 \pm 13.5^{2}$ \\
\hline \multicolumn{6}{c}{${ }^{1}$ Selmer et al. [6], ${ }^{2}$ Kleemann et al. [38]. }
\end{tabular}

The values reveal that for EWP gels, the stiffness increased by a factor of up to $10^{2}$ from the hydrogel to the alcogel state. The stiffness was doubled at most from the alcogel to the aerogel state. This shows that a substantial part of the structural changes already occurred during the solvent exchange. A similar effect was observed with WPI. The relative effect of $\mathrm{scCO}_{2}$ drying is higher for WPI gels than for EWP gels, but a major effect of the solvent exchange is visible. It is undoubted that the $\mathrm{scCO}_{2}$ drying induces further changes because the gel changes from the typical gel character containing a liquid into a liquid-free solid material. On the insights gained in this study, we can state that the $\mathrm{scCO}_{2}$ process seems to be of minor effect to the shrinkage and hardening of the protein gels, but rather enforces changes, which are to a major extent induced by the solvent exchange. This can be derived from the fact that the aerogel properties resemble most of the properties already observed for the alcogel. Most changes can therefore be attributed to the solvent exchange step. This is a major difference to silica aerogels, where the gel formation is typically performed directly in methanol or ethanol and all shrinkage can be attributed to the supercritical drying step [39]. The newly formed and strengthened interactions in the gel structures due to the solvent exchange of water with $\mathrm{EtOH}$ are, therefore, most important for the properties of supercritically dried protein aerogels.

\section{Materials and Methods}

\subsection{Materials}

Pasteurized egg white was provided by Ovobest Eiprodukte GmbH \& Co. KG (Neuenkirchen-Vörden, Germany). Whey protein isolate powder with a protein content of $94 \%$ was obtained from Davisco Foods International Inc. (Eden Prairie, MN, USA). Commercial sunflower oil was sourced from a local store (Bröckelmann + CO, Hamm, Germany). EtOH (99.95\% purity) was obtained from VWR Chemicals (Leuven, Belgium). Hydrochloric acid and sodium hydroxide came from Merck KGaA (Darmstadt, Germany). Perchloric acid 60\% to dissolve ions as well as sulfuric acid $0.4 \mathrm{mM}$ and oxalic acid $2.3 \mathrm{mM}$ as eluent for HPLC were purchased from Merck KGaA (Darmstadt, Germany). Sodium IC standard solution and potassium AAS standard solution came from Carl Roth GmbH (Karlsruhe, Germany) and calcium chloride dihydrate from Sigma-Aldrich (Saint Louis, MO, USA). All chemical agents were of analytical grade. Buffers and solutions were prepared with deionized water (Milli $Q$ Integral 3, Merck KGaA, Darmstadt, Germany).

\subsection{Methods}

\subsubsection{Preparation of Spherical Protein Hydrogel Samples}

Protein hydrogel spheres with a diameter of $5 \mathrm{~mm}$ were produced using a method developed by the authors in the course of this research project. The volume of a $5 \mathrm{~mm}$ sphere was pipetted into a hemispherical teflon mold and immersed in heated sunflower oil for thermal gelation, as depicted in Figure 4. Supported by the mold, the interfacial tension between oil and aqueous protein solution forces the sample into a spherical shape. The method allows the production of macroscopic gel samples, under conditions as close as possible to particles produced by the emulsion gelation method. The WPI solution had a protein concentration of $20 \%$, which is sufficient to form inherently stable hydrogels [40]. 
EWP hydrogels were formed with the native protein content of pasteurized egg white, determined to $10.1 \%$. The $\mathrm{pH}$ of the respective protein solutions was adjusted to the specified value. The $\mathrm{pH}$ values chosen were the native $\mathrm{pH}$ of the respective protein solution (WPI: $\mathrm{pH} 7.0, \mathrm{EWP}: \mathrm{pH}$ 9.0) and the highest possible $\mathrm{pH}$ prior to a fast alkaline gel formation (WPI: $\mathrm{pH}$ 10.0, EWP: $\mathrm{pH}$ 11.0) The $\mathrm{pH}$ levels in this study always refer to the respective aqueous protein solution prior to gel formation. Hydrogel samples were stored at $4{ }^{\circ} \mathrm{C}$ in sunflower oil to prevent dehydration until further use or characterization.

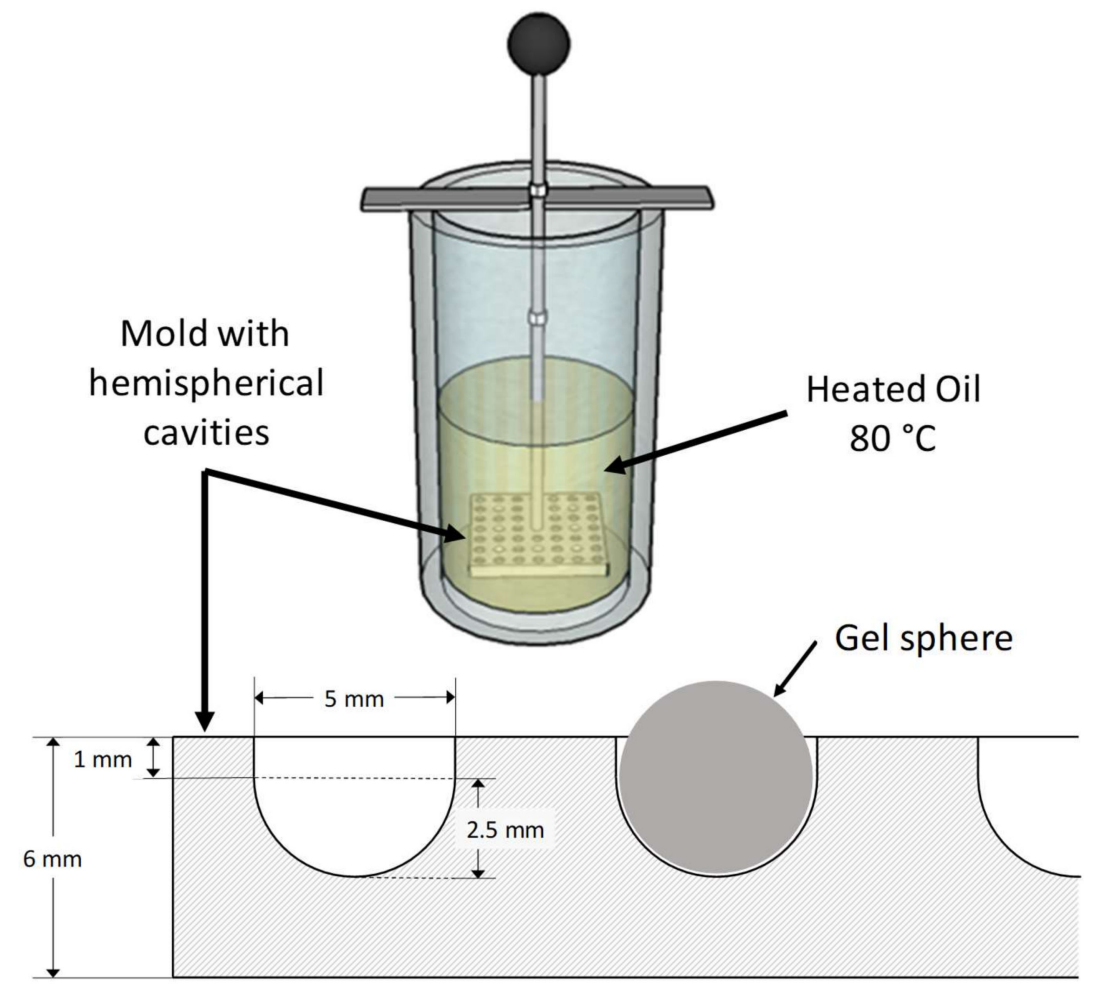

Figure 4. Oil bath and sectional drawing of mold for sample preparation of spherical protein gels with a diameter of $5 \mathrm{~mm}$.

\subsubsection{Solvent Exchange of Water by EtOH}

The sphere was chosen as a sample geometry since it is the only geometry that undergoes isotropic expansion or shrinkage during swelling or de-swelling [41]. The solvent exchange with EtOH was started by removing the samples from the oil and blotting them with a lint-free paper towel. Single gel samples were transferred into $2 \mathrm{~mL}$ vials. The vials were then filled with $2 \mathrm{~mL}$ of the respective aqueous EtOH solution containing $60 \%$ to $100 \% \mathrm{EtOH}(w / w)$. The vials were kept under constant agitation in order to minimize concentration gradients. For a complete solvent exchange, the samples were kept in the exchange solution for at least $4 \mathrm{~h}$ before the solution was exchanged, which was repeated in triplicate, according to Kleemann et al. [38]. The final EtOH content of the samples was determined indirectly with a density meter DM4100 (Anton Paar GmbH, Graz, Austria) by measuring the EtOH concentration of the solution after the respective exchange step. Samples were stored at $4{ }^{\circ} \mathrm{C}$ in the final $\mathrm{EtOH}$ solution until further characterization.

\subsubsection{Physical Characterization of Spherical Samples}

Prior to structural characterization, the samples were tempered at $20{ }^{\circ} \mathrm{C}$ for $1 \mathrm{~h}$. The samples were removed from the respective storage fluid, blotted with a lint-free paper towel and analyzed immediately to avoid drying up. To determine the textural properties of the gel spheres, a texture analyzer TA.XT.plus (Stable Micro Systems, Vienna Court, UK) with an acrylic cylinder probe (diameter $13 \mathrm{~mm}$ ) was used. Pre-test speed, test speed and post-test speed of the probe were all set to $0.1 \mathrm{~mm} / \mathrm{s}$. 
The height of the probe at the first sign of a counteracting force was used to determine the diameter of the samples. A texture profile analysis (TPA) measurement according to Bourne [42] was conducted to measure the hardness of the samples. The hardness was defined as the force needed to deform the spherical samples by $60 \%$ of their original height. The strain of $60 \%$ was chosen because some alcogels revealed fracture peaks if a strain of $70 \%$ was exceeded. The elasticity as a measure of sample recovery after deformation was expressed as the ratio of the height of the sample at the second compression cycle to the height at the first compression cycle with $60 \%$ strain and 5 s recovery time between the cycles.

\subsubsection{Measurement of Dissolved Ions from Protein Gel Structure during Solvent Exchange}

Gel spheres were produced according to Section 4.2.1. The WPI solution had a $\mathrm{pH}$ of 7 , and the EWP solution had a $\mathrm{pH}$ of 9 prior to gel formation. Directly after sample production, 10 gel spheres were placed into $10 \mathrm{~mL}$ vials with $4 \mathrm{~mL}$ of exchange solution. The exchange solutions were: deionized water, $60 \%$ aqueous $\mathrm{EtOH}$ solution or $99.95 \% \mathrm{EtOH}$ solution. The solvent exchange was then conducted during $24 \mathrm{~h}$ at $4{ }^{\circ} \mathrm{C}$ under constant agitation to minimize concentration gradients and microbial growth. This exchange time was chosen since it allowed the detection of the ions in each sample. Shorter exchange times and a repetitive renewal of the exchange solution, as conducted for the complete solvent exchange (Section 4.2.2), would have reduced the content of ions below the detection limit. After the exchange time, the gel samples were removed from the exchange solution, and weight and density (DM 4100, Anton Paar GmbH, Graz, Austria) of the solution were determined. Due to incompatibility of EtOH and the HPLC analysis of cations, the entire exchange solution was evaporated in a vacuum dryer (VO Cool, Memmert GmbH \& Co.KG, Schwabach, Germany) overnight at 80 mbar and $50{ }^{\circ} \mathrm{C}$. The remaining ions were then re-dissolved by the addition of $2 \mathrm{~mL}$ deionized water and $100 \mu \mathrm{L}$ of $60 \%$ perchloric acid, which also dissolved and denatured residual proteins in the vials, which were inevitably found as traces of the gel spheres after the solvent exchange. After a dissolution time of $10 \mathrm{~min}$, another $6 \mathrm{~mL}$ of deionized water was added and the samples were centrifuged with a $10 \mathrm{kDa}$ centrifugal filter (VWR Centrifugalfilter $10 \mathrm{kDa}, 500 \mu \mathrm{L}$, VWR International, Radnor, PA, USA) at a relative centrifugal force of $14,000 \times g$ during $10 \mathrm{~min}$. The filtrate was diluted at a ratio of 1:1 with deionized water to perform HPLC-analysis. A PRP-X800 column for isocratic separation of mono- and di-valent cations was used to determine the ion concentration of $\mathrm{Na}^{+}, \mathrm{K}^{+}$and $\mathrm{Ca}^{2+}$. Potassium was below the detection limit for WPI samples. The concentration determined with HPLC analysis allowed to calculate the absolute weight of ions in the vials after evaporation. Using the absolute weight of ions, the concentration of ions in the solution after the solvent exchange was calculated, using the volume of the exchange solution, determined by its mass and density.

\subsubsection{Determination of Extracted Ions from Protein Gel during Solvent Exchange}

The ions in the precursor protein solutions, used for the hydrogel preparation, were determined by applying the same method as described in Section 4.2.4. In brief, $200 \mathrm{mg}$ of the protein solutions were placed in a vacuum dryer to evaporate the water. By the addition of deionized water and perchloric acid, the ions were dissolved, and the proteins precipitated prior to centrifugation with centrifugal filters. The concentration of ions in the filtrate was determined by HPLC analysis. Using this concentration, the absolute weight of residual ions in the vials after evaporation and, hence, the concentration in the precursor protein solution was calculated. This allowed to calculate the mass of ions contained in the gel samples prior to the solvent exchange (Section 4.2.4). The percentage of extracted ions from the gel samples was calculated as the ratio of the mass of ions contained in the exchange solution and the mass of ions in the gel samples before the solvent exchange.

$$
\text { Extracted ions }[\%]=\frac{m_{\text {ions in exchange solution }}}{m_{\text {ions in gel before solvent exchange }}} \cdot 100
$$




\subsubsection{Statistical Evaluation and Data Presentation}

All experiments were executed at least in triplicate. The standard for texture analyzer data points in this study was the measurement of five individual samples. Error bars in the graphs represent the standard deviation. Absolute values are given as the mean value of repetitions \pm standard deviation.

\section{Conclusions}

With this study, the knowledge about the effect of EtOH on proteins has been extended from proteins in solution to proteins immobilized in heat-denatured gels based on different proteins and produced at different $\mathrm{pH}$ conditions. In particular, we can conclude based on the results presented here, on hydrogels exposed to solvent exchange and in previous works on aerogel structures, that most of the hardening and shrinkage occurs early in the process during solvent exchange and hardly during $\mathrm{scCO}_{2}$ drying of alcogels.

Author Contributions: Conceptualization, C.K., J.Z. and I.S. (Ilka Selmer); Funding acquisition, I.S. (Irina Smirnova) and U.K.; Investigation, C.K. and J.Z.; Methodology, C.K. and J.Z.; Project administration, C.K. and I.S. (Ilka Selmer); Resources, U.K.; Supervision, I.S. (Irina Smirnova) and U.K.; Validation, C.K., J.Z. and I.S. (Ilka Selmer); Visualization, C.K. and J.Z.; Writing-original draft, C.K. and J.Z.; Writing-review and editing, I.S. (Ilka Selmer), I.S. (Irina Smirnova) and U.K. All authors have read and agreed to the published version of the manuscript.

Funding: This IGF Project (AiF17485N) of the FEI was supported via AiF within the program for promoting the Industrial Collective Research (IGF) of the German Ministry of Economic Affairs and Energy (BMWi), based on a resolution of the German Parliament.

Conflicts of Interest: The authors declare no conflict of interest. The funders had no role in the design of the study; in the collection, analyses, or interpretation of data; in the writing of the manuscript, or in the decision to publish the results.

\section{References}

1. Yoshizawa, S.; Arakawa, T.; Shiraki, K. Dependence of ethanol effects on protein charges. Int. J. Biol. Macromol. 2014, 68, 169-172. [CrossRef] [PubMed]

2. Moe, S.T.; Skjaak-Braek, G.; Elgsaeter, A.; Smidsroed, O. Swelling of covalently crosslinked alginate gels: Influence of ionic solutes and nonpolar solvents. Macromolecules 1993, 26, 3589-3597. [CrossRef]

3. Sason, G.; Nussinovitch, A. Characterization of $\mathrm{k}$-carrageenan gels immersed in ethanol solutions. Food Hydrocoll. 2018, 79, 136-144. [CrossRef]

4. Betz, M.; García-González, C.A.; Subrahmanyam, R.; Smirnova, I.; Kulozik, U. Preparation of novel whey protein-based aerogels as drug carriers for life science applications. J. Supercrit. Fluids 2012, 72, 111-119. [CrossRef]

5. García-González, C.A.; Alnaief, M.; Smirnova, I. Polysaccharide-based aerogels—Promising biodegradable carriers for drug delivery systems. Carbohydr. Polym. 2011, 86, 1425-1438. [CrossRef]

6. Selmer, I.; Kleemann, C.; Kulozik, U.; Heinrich, S.; Smirnova, I. Development of egg white protein aerogels as new matrix material for microencapsulation in food. J. Supercrit. Fluids 2015, 106, 42-49. [CrossRef]

7. Stergar, J.; Maver, U. Review of aerogel-based materials in biomedical applications. J. Sol.-Gel Sci. Technol. 2016, 77, 738-752. [CrossRef]

8. Selmer, I.; Karnetzke, J.; Kleemann, C.; Lehtonen, M.; Mikkonen, K.S.; Kulozik, U.; Smirnova, I. Encapsulation of fish oil in protein aerogel micro-particles. J. Food Eng. 2019, 260, 1-11. [CrossRef]

9. Takeshita, S.; Sadeghpour, A.; Malfait, W.J.; Konishi, A.; Otake, K.; Yoda, S. Formation of Nanofibrous Structure in Biopolymer Aerogel during Supercritical CO2 Processing: The Case of Chitosan Aerogel. Biomacromolecules 2019, 20, 2051-2057. [CrossRef]

10. Subrahmanyam, R.; Gurikov, P.; Dieringer, P.; Sun, M.; Smirnova, I. On the Road to Biopolymer Aerogels-Dealing with the Solvent. Gels 2015, 1, 291-313. [CrossRef]

11. Gurikov, P.; Subrahmanyam, R.; Griffin, J.S.; Steiner, S.A.; Smirnova, I. 110th Anniversary: Solvent Exchange in the Processing of Biopolymer Aerogels: Current Status and Open Questions. Ind. Eng. Chem. Res. 2019, 58, 18590-18600. [CrossRef] 
12. Havea, P.; Watkinson, P.; Kuhn-Sherlock, B. Heat-induced whey protein gels: Protein-protein interactions and functional properties. J. Agric. Food Chem. 2009, 57, 1506-1512. [CrossRef] [PubMed]

13. Mohsen-Nia, M.; Amiri, H. Measurement and modelling of static dielectric constants of aqueous solutions of methanol, ethanol and acetic acid at $\mathrm{T}=293.15 \mathrm{~K}$ and $91.3 \mathrm{kPa}$. J. Chem. Thermodyn. 2013, 57, 67-70. [CrossRef]

14. Løkra, S.; Helland, M.H.; Claussen, I.C.; Strætkvern, K.O.; Egelandsdal, B. Chemical characterization and functional properties of a potato protein concentrate prepared by large-scale expanded bed adsorption chromatography. Lwt-Food Sci. Technol. 2008, 41, 1089-1099. [CrossRef]

15. Uversky, V.N.; Narizhneva, N.V.; Kirschstein, S.O.; Winter, S.; Löber, G. Conformational transitions provoked by organic solvents in $\beta$-lactoglobulin: Can a molten globule like intermediate be induced by the decrease in dielectric constant? Fold. Des. 1997, 2, 163-172. [CrossRef]

16. Cassanelli, M.; Norton, I.; Mills, T. Effect of alcohols on gellan gum gel structure: Bridging the molecular level and the three-dimensional network. Food Struct. 2017, 14, 112-120. [CrossRef]

17. Boral, S.; Gupta, A.N.; Bohidar, H.B. Swelling and de-swelling kinetics of gelatin hydrogels in ethanol-water marginal solvent. Int. J. Biol. Macromol. 2006, 39, 240-249. [CrossRef]

18. Dufour, E.; Robert, P.; Renard, D.; Llamas, G. Investigation of $\beta$-Lactoglobulin Gelation in Water/Ethanol Solutions. Int. Dairy J. 1998, 8, 87-93. [CrossRef]

19. Zirbel, F.; Kinsella, J.E. Effects of thiol reagents and ethanol on strength of whey protein gels. Food Hydrocoll. 1988, 2, 467-475. [CrossRef]

20. Yao, L.; Jiang, A.; Chen, L. Characterization of ethanol-induced egg white gel and transportation of active nutraceuticals. Lwt-Food Sci. Technol. 2020, 130, 109530. [CrossRef]

21. Hirota-Nakaoka, N.; Goto, Y. Alcohol-induced denaturation of $\beta$-lactoglobulin: A close correlation to the alcohol-induced $\alpha$-helix formation of melittin. Bioorganic Med. Chem. 1999, 7, 67-73. [CrossRef]

22. Yoshikawa, H.; Hirano, A.; Arakawa, T.; Shiraki, K. Effects of alcohol on the solubility and structure of native and disulfide-modified bovine serum albumin. Int. J. Biol. Macromol. 2012, 50, 1286-1291. [CrossRef] [PubMed]

23. Dufour, E.; Haertl', T. Alcohol-induced changes of $\beta$-lactoglobulin-retinol-binding stoichiometry. Protein Eng. Des. Sel. 1990, 4, 185-190. [CrossRef] [PubMed]

24. Mine, Y. Recent advances in the understanding of egg white protein functionality. Trends Food Sci. Technol. 1995, 6, 225-232. [CrossRef]

25. Farrell, H.M.; Jimenez-Flores, R.; Bleck, G.T.; Brown, E.M.; Butler, J.E.; Creamer, L.K.; Hicks, C.L.; Hollar, C.M.; Ng-Kwai-Hang, K.F.; Swaisgood, H.E. Nomenclature of the Proteins of Cows' Milk-Sixth Revision. J. Dairy Sci. 2004, 87, 1641-1674. [CrossRef]

26. Khokhlov, A.R.; Philippova, O.E.; Sitnikova, N.L.; Starodubtsev, S.G. Supramolecular structures in polyelectrolyte gels. Faraday Disc. 1995, 101, 125. [CrossRef]

27. Betz, M.; Hörmansperger, J.; Fuchs, T.; Kulozik, U. Swelling behaviour, charge and mesh size of thermal protein hydrogels as influenced by $\mathrm{pH}$ during gelation. Soft Matter 2012, 8, 2477. [CrossRef]

28. Gunasekaran, S.; Ko, S.; Xiao, L. Use of whey proteins for encapsulation and controlled delivery applications. J. Food Eng. 2007, 83, 31-40. [CrossRef]

29. Pinho, S.P.; Macedo, E.A. Solubility of $\mathrm{NaCl}, \mathrm{NaBr}$, and $\mathrm{KCl}$ in Water, Methanol, Ethanol, and Their Mixed Solvents. J. Chem. Eng. Data 2005, 50, 29-32. [CrossRef]

30. Koseki, T.; Kitabatake, N.; Doi, E. Irreversible thermal denaturation and formation of linear aggregates of ovalbumin. Food Hydrocoll. 1989, 3, 123-134. [CrossRef]

31. Shimada, K.; Cheftel, J.C. Texture characteristics, protein solubility, and sulfhydryl group/disulfide bond contents of heat-induced gels of whey protein isolate. J. Agric. Food Chem. 1988, 36, 1018-1025. [CrossRef]

32. Petit, J.; Herbig, A.-L.; Moreau, A.; Delaplace, G. Influence of calcium on $\beta$-lactoglobulin denaturation kinetics: Implications in unfolding and aggregation mechanisms. J. Dairy Sci. 2011, 94, 5794-5810. [CrossRef] [PubMed]

33. Doi, E.; Kitabatake, N. Structure of glycinin and ovalbumin gels. Food Hydrocoll. 1989, 3, 327-337. [CrossRef]

34. Handa, A.; Takahashi, K.; Kuroda, N.; Froning, G.W. Heat-induced Egg White Gels as Affected by pH. J. Food Sci. 1998, 63, 403-407. [CrossRef]

35. Jukes, T.H.; Schmidt, C.L.A. The apparent dissociation constants of certain amino acids and related substances in water-ethanol mixtures. J. Biol. Chem. 1934, 105, 359-371. 
36. Gelsema, W.J.; De Ligny, C.L.; Van der Veen, N.G. Isoelectric points of proteins, determined by isoelectric focusing in the presence of urea and ethanol. J. Chromatogr. A 1979, 171, 171-181. [CrossRef]

37. Van der Plancken, I.; Van Loey, A.; Hendrickx, M.E.G. Changes in sulfhydryl content of egg white proteins due to heat and pressure treatment. J. Agric. Food Chem. 2005, 53, 5726-5733. [CrossRef]

38. Kleemann, C.; Selmer, I.; Smirnova, I.; Kulozik, U. Tailor made protein based aerogel particles from egg white protein, whey protein isolate and sodium caseinate: Influence of the preceding hydrogel characteristics. Food Hydrocoll. 2018, 83, 365-374. [CrossRef]

39. Maleki, H.; Durães, L.; Portugal, A. An overview on silica aerogels synthesis and different mechanical reinforcing strategies. J. Non-Cryst. Solids 2014, 385, 55-74. [CrossRef]

40. Betz, M.; Kulozik, U. Whey protein gels for the entrapment of bioactive anthocyanins from bilberry extract. Int. Dairy J. 2011, 21, 703-710. [CrossRef]

41. Kurnia, J.C.; Birgersson, E.; Mujumdar, A.S. Finite deformation of fast-response thermo-sensitive hydrogels-A computational study. Polymer 2012, 53, 2500-2508. [CrossRef]

42. Bourne, M.C. Food Texture and Viscosity. Concept and Measurement; Academic Press: San Diego, CA, USA, 2002; ISBN 0121190625.

Sample Availability: Samples of the compounds are not available from the authors. 